Revista Portuguesa de História

t. XXXI, Vol. I(1996)

\title{
NOTAS SOBRE A PRODUÇÃO DE SAL-GEMA E DE PAPEL EM LEIRIA E EM COIMBRA DURANTE A IDADE MÉDIA
}

SAUL ANTÓNIO GOMES

(Universidade de Coimbra)

\section{1 -A exploração de sal-gema.}

São abundantes as notícias sobre a produção de sal no Portugal dos séculos XII e XIII. Tanto se produzia sal por evaporação, aproveitando a orla costeira atlântica, como por extracção do sub-solo, através da captação dos poços de sal-gema.

$\mathrm{Na}$ orla costeira minhota atesta-se desde o século $\mathrm{X}$, e especialmente nos séculos XI e XII, a salinicultura nas embocaduras dos rios Minho, Lima, Cávado, Ave, Leça e Douro (Miragaia e Massarelos)'. Em Esgueira (Aveiro), nos séculos XI a XIII, os

Virgínia Rau, Estudos sobre a História do Sal Português, Lisboa, Presença, 1984, pp. 54-57; Rosa Marreiros, "Pesca e Salinicultura - o Sal", Portugal em Definição de Fronteiras do Condado Portucalense à Crise do Século XIV (coord. de Maria Helena da Cruz Coelho e Armando Luís de Carvalho Homem), Vol. III de Nova História de Portugal (dir. A.H. de Oliveira Marques e Joel Serrão), Lisboa, Presença, 1996, pp. 451-454; Carlos Alberto de Almeida, «Salinas Medievais entre o Cávado e o Neiva», Bracara Augusta, vol. XXXIII (1979), pp. 391-401. 
talhos de marinha multiplicavam-se por centenas, possuídas por particulares, clérigos e instituições religiosas (Lorvão, Vacariça, St. $^{a}$ Cruz e Sé de Coimbra) ${ }^{2}$. Na Aveiro dos séculos XI e XII proliferavam as salinas que se estendiam a Sá, Ovar, Ílhavo e Vagos disputadas por proprietários alodiais e eclesiásticos (nestes, uma vez mais, evidenciaram-se os cistercienses Mosteiros de Celas de Coimbra, de Lorvão e de S. João de Tarouca), documentando-se marinhas de 12 ou 15 talhos $^{3}$.

Em Coimbra, a actividade salinífera documenta-se desde épocas muito recuadas. No século XII, exploravam-se marinhas de sal em Lavos, Oveiroa (Morraceira), Tavarede, Caceira e foz do Mondego. Entre os seus principais proprietários, que as procuravam valorizar de forma muito empenhada, atendendo aos benefícios certos e lucrativos que o produto lhes proporcionava, encontravam-se primeiramente herdadores e clérigos, seguidos pelo Mosteiro de St. ${ }^{a}$ Cruz, pelo Cabido da Sé, pelo Mosteiro de S. Jorge e por algumas outras instituições regulares (Celas, Seiça, S. Paulo de Almaziva, Templários) e seculares (S. Pedro, S. Salvador).

$\mathrm{Na}$ região mondeguina detecta-se um surto sustentado na multiplicação de marinhas ao longo de Duzentos, surgindo então numerosas referências a marinhas novas, exploradas segundo diversificadas condições negociadas entre senhorios e foreiros. As marinhas eram organizadas segundo técnicas de trabalho imemoriais que os marnoteiros transmitiam entre si. O trabalho da extracção do sal, contudo, dificilmente é alvo de descrição nos

Maria João Branco Silva, Esgueira. A vida de uma aldeia do século XV, Redondo, Patrimonia, 1994, pp. 47-48, 123-133.

Virgínia Rau, op. cit., pp. 58-61; Maria João Branco Silva, Aveiro Medieval. Aveiro, Câmara Municipal, 1991, pp. 96-104. 
documentos. Estes estão cheios de indicações sobre o domínio da propriedade salinífera, os custos da sua exploração, as exigências relativas aos pagamentos das rendas ou foros e dos dízimos paroquiais devidos. Por eles se vê que as marinhas de sal eram caracterizadas por uma extrema fragmentação das suas parcelas ou talhos, só compensada pelo elevadíssimo preço que as suas unidades atingiam no mercado predial. Uma marinha de 18 talhos valia 220 morabitinos de ouro em 1238, enquanto uma outra de 30 talhos poderia ser vendida, em 1241, por 120 morabitinos. Diferenças de preços que deixam indiciar desiguais capacidades de produção, decerto, tanto quanto demonstram a pluralidade das capacidades de negociação, de compra e venda que as partes interessadas alcançavam ${ }^{4}$.

Santa Maria de Alcobaça explorava salinas marítimas em Alfeizerão, em S. Martinho do Porto e nas zonas da Serra do Bouro e de Salir do Porto (concelhos de Óbidos e de Caldas da Rainha). O Mosteiro contava ainda com salinas em Atouguia (da Baleia) e em Lisboa. Em Rio Maior extraía sal-gemas.

Nas salinas do estuário do Tejo, o quadro da propriedade salinífera não destoava muito do que vimos para o centro do País. O monarca, contudo, surge entre um dos maiores proprietários de marinhas, devidamente acolitado pelos institutos religiosos (Mosteiros de S. Vicente, das Donas de Cheias e S. Dinis de Odivelas). $\mathrm{Na}$ margem esquerda, a Ordem de Santiago impulsionou o aparecimento de bom número de póvoas ribeirinhas (Montijo,

“ Ver Maria Helena Coelho, O Baixo Mondego nos Finais da Idade Média (Estudo de História Rural), Coimbra, Faculdade de Letras, 1983, pp. 255-259; Virgínia Rau, Estudos Sobre a História do Sal Português, Lisboa, Presença, 1984, pp. 61-62.

${ }^{5}$ Virgínia Rau, op. cit., pp. 62-64. 
Alcochete, Sarilhos, Aldeia Galega), onde habitavam marnotos que velavam pelas salinas daquele senhorio. No vale do Sado desenvolveram-se paulatinamente condições para produção de sal de excelente qualidade e em quantidades que excediam largamente as necessidades locais, sendo canalizadas para mercados exteriores, particularmente para Lisboa ${ }^{6}$. Também no Algarve se concentravam importantes marinhas saliníferas, reservando os monarcas portugueses o monopólio da concessão da respectiva exploração?

A exploração de sal-gema permitia ao Mosteiro de St. ${ }^{a}$ Cruz de Coimbra bons réditos na zona de Leiria, onde recolhia o dízimo das salinas ("sentas") de Brancas e Alcanadas (c. Batalha), Cirol e Porto Moniz-Cubelo (c. Leiria), além das dízimas régias sobre esse mesmo produto que D. Sancho I, D. Sancho II e D. Afonso III outorgaram àquela mesma instituição ${ }^{8}$. A extracção do sal-gema e a sua comercialização levavam a uma especialização de mão-de-obra, aparecendo, na região leiriense, os "senteiros" dedicados ao fabrico deste tipo de sal'

O negócio do sal-gema na Leiria medieva interessava a própria aristocracia residente. Um dos vultos dominantes na documentação, sobre este aspecto, era o de D. Beatriz Dias, antiga "manceba" do rei $\mathrm{D}$. Pedro $\mathrm{I}^{10}$ e riquíssima proprietária na cidade e no seu

${ }^{6}$ Virgínia Rau, op. cit., pp. 64-70.

'Gama Barros, História da Administração Pública em Portugal nos Séculos XII a $X V$, 2. ${ }^{\text {a }}$ ed., (dir. Torquato de Sousa Soares), Lisboa, Sá da Costa, 1945-54, vol. IX, pp. 236-298.

${ }^{\circ}$ ANTT-St. ${ }^{a}$ Cruz de Coimbra, $1 .^{a}$ incorp., m. ${ }^{\circ} 4, \mathrm{n}^{\circ} 38$ (1223-1245), VIII. 17); Id., ibidem, m. ${ }^{\circ} 3, \mathrm{n}^{\circ} 5$ (1253, X, 21); Id., Most. de Alcobaça, $2 .^{\mathrm{a}}{ }^{\circ}$ incorp., ${ }^{\circ} 15, \mathrm{n}^{\circ} 364$ (13) (1362.III.8).

Caso de João Alho, senteiro, morador em Leiria e proprietário de uma vinha em Alpentende (freg ${ }^{a}$ Golpilheira, c. Batalha) (ANTT-St. ${ }^{a}$ Clara de Coimbra, m. ${ }^{\circ} 2$, n. $^{\circ} 4$ (1337.I.16))

${ }^{10}$ Sobre esta mulher que privava, como jovem concubina, na corte de D. Pedro I, escreve fugazmente Fernão Lopes: "E porque um seu escrivão do tesouro recebeu onze 
termo. Foi a ela que aquele rei doou a Quinta do Cirol (freg ${ }^{\mathrm{a}}$ Caranguejeira, c. Leiria) na qual existiam salinas de bom sal".

Publicado o seu testamento em 26 de Fevereiro de 1383, no Mosteiro de Alcobaça, por Gomes Lourenço, seu testamenteiro e capelão, dele constavam as "seentas do sall d Alcanada com sua casa e com suas herdades", bem como, na cidade de Leiria, "a casa do sal que esta na dicta vylla na rrua da rrigueira" ${ }^{\prime 2}$. Compunham estas "sentas" 15 talhos de sal e um "vineiro", que interpretamos como caneiro ou conduta das águas salobras extraídas do subsolo pela abertura de um poço ${ }^{13}$. Que o negócio do sal era rentável para esta "criada" de D. Pedro I verificava-se já pela doação que esse mesmo monarca lhe fizera, em 10 de Maio de 1363, da Quinta da Lançada, no Ribatejo, a par de Sarilhos, "com suas salinas de sal"14.

As salinas de Beatriz Dias, situadas no termo de Leiria, foram deixadas por ela ao Mosteiro de Alcobaça, a fim de se retirarem das suas rendas, bem como de mais algumas outras propriedades, o dinheiro necessário para custeamento de certas capelas e missas

libras e meia sem o tesoureiro, mandou-o enforcar, que lhe não pode valer o conde nem Beatriz Dias, manceba del-rei, nem outro nenhum." (Crónica de D. Pedro (org. de António Borges Coelho), Lisboa, Livros Horizonte, 1977, cap ${ }^{\circ}$ IX, p. 66). Vd. também Rita Costa Gomes, A Corte dos Reis de Portugal no Final da Idade Média, Lisboa, Difel, 1995, pp. 60, 164.

"ANTT-Most. de Alcobaça, $2^{a}$ incorp., M. ${ }^{\circ}$ 15, n. ${ }^{\circ} 364$ (13). (1362.II1.8,Tentúgal). Publicado, mas a partir do registo da chancelaria de D. Pebro, em Chancelarias Portuguesas - D. Pedro I (1357-1367), (org. A. H. Oliveira Marques et alii), Lisboa, INIC - Univ. Nova de Lisboa, 1984, pp. 365-366. (Esta Quinta fora pertença de João Esteves Casqueiro, almoxarife de D. Afonso IV, em Leiria.)

${ }^{12}$ ANTT-Most. de Alcobaça, $2^{a}$ - incorp., m. ${ }^{\circ}$ 9, n. 216 (5) e ${ }^{\circ} 220$ (9); Id., ibidem. Dourados, Livro 3, fls. 85-87.

ANTT-Most. de Alcobaça, 2a - inc, M. ${ }^{\circ}$ 19, n. 445 (13) (9.III.1383).

${ }^{\prime 4}$ Chancelarias Portuguesas - D. Pedro I, p. 220. Além de salinas, Beatriz Dias possuía a Lezíria do Galego, no termo de Santarém, abaixo dos paços reais da Valada (doada por D. Pedro I em 17.IV. 1365 e coutada pelo mesmo em 11 de Junho seguinte) (Chanc. de D. Pedro..., pp. 468, 482, 583). 
instituídas por sua alma e pela do seu "senhor" el-rei D. Pedro I. Em 1397, o Mosteiro de Alcobaça procedeu ao aforamento de "dezasete talhos que nos e o dicto nosso Mosteiro auemos em as sseentas do sal termho outrossy da dicta vila de Leirea com huã casa e com huum conchouso". Estas salinas partiam com rio, com alguns outros proprietários e "caminho de hereos". Entre as obrigações do contrato enfitêutico constava o dever do foreiro fazer e refazer "a dicta nossa casa de Seentas e os dictos talhos de Seentas de todo adubio que lhis cumprir"15.

As salinas de Alcanada (ou de A-das-Brancas, hoje freguesia da Batalha) eram porventura das mais apetecidas da região. Nela senhoriavam interesses e direitos, além de bom número de particulares vilãos, como Lopo Vasques e Mestre Rodrigo, mesteirais das obras da Batalha por $1446^{16}$, ou o concelho de Leiria ${ }^{17}$, senhorios monásticos, que não só Alcobaça, como Santa Cruz de Coimbra $^{18}$ ou Santa Maria da Vitória ${ }^{19}$. Perto dessa povoação, no

${ }^{15}$ ANTT-Most. de Alcobaça, Livro 183, doc. 111, fls. 51v ${ }^{\circ}-52$. (24.1.1397).

"Saul Gomes, O Mosteiro de Santa Maria da Vitória no Século XV Coimbra, Instituto de História da Arte da Faculdade de Letras, 1990, pp. 205-206.

"Nas Cortes de Lisboa de 1498, os procuradores de Leiria reclamaram, do rei, a resolução de questões sobre os direitos do "poço do sall". A questão é formulada, certamente, no contexto da elevação da Batalha a concelho, garantindo a autarquia leiriense, em 1500, a jurisdição concelhia sobre A-das-Brancas onde se situava o mencionado "poço do sal". Cite-se: "(...) posto que dentro fique [do novo concelho da Batalha] as semtas honde se faz o sal quanto monta soomente a servidão e loguo dellas e fazjmento do sal porquanto a administraçam delias he de Leyria e de sua camara e a ella queremos e nos praz que fiquem e as gouernem como sempre fezerom e teem per seus privilegios e boons customes e proueito da Republica". (ANTT-Corpo Cronológico, Parte I, m. ${ }^{\circ}$ 2, doc. 212 (28.III.1498), Id., Estremadura, Livro 1, fls. 276vº-277 (17.III.1500)). Vd. O Mosteiro de Santa Maria da Vitória...., pp. 54-61.

${ }^{18}$ Por 1400, um Diogo Vicente Pardinho, do Arrabalde da Ponte, Leiria, trazia de Santa Cruz "tres talhos de sal nas seentas d alcanada e binha e herdade hu chamam a cabreira tem todo por 1x libras desta moeda". [Real de 10 soldos]; pela mesma época ou pouco mais tarde, precisamente em 1431, ali trazia uma outra vinha de Santa Cruz um Estêvão Domingues Rangel. (ANTT-Santa Cruz de Coimbra, Livro 94, fls. 279,284).

${ }^{19}$ Propriedades já por mim arroladas no meu livro $O$ Mosteiro de Santa Maria da Vitória..., pp. 205-206. 
lugar de Cela, fazia-se também extracção de sal-gema, como se prova pela marinha de sal que ali tinha o Mosteiro de Alcobaça em $1435^{20}$, ou, ainda, pela notícia, datada de 1472 , de "huã heira de joham afomso da çella em que se poem sal"21.

A nomenclatura documental medieva sobre as salinas de sal-gema da região leiriense usa, além de "sentas", a palavra "marinha". Foi desta palavra, seguramente, que nasceu o topónimo da actual cidade da Marinha Grande, registado já em documento de 1416, onde habitava João Cordeiro que aforou de Alcobaça, naquela data, o Casal da Melvoa, não muito distante do lugar da "Marinha"22.

Junto à cidade de Leiria procedia-se à extracção de sal-gema em Porto Moniz, desenvolvendo-se alguma habitação nas proximidades do local, situado que estava dentro do subúrbio da paróquia de Santo Estêvão. Nas "Seentas hu chamam o Casal" habitava Lourenço Eanes, moleiro, em $1366^{23}$. Junto a estas salinas existiam vinhas e pomares, caso de "huã binha nas seentas aso santo esteuam" ou duma outra trazida por Álvaro Soupana, morador em Santo Estêvão, com renda de 20 libras mais dízimo, que pertenciam a Santa Cruz de Coimbra ${ }^{24}$, ou ainda aqueloutra "vynha com suas aruores que a dicta Ordem [St. ${ }^{a}$ Clara de Coimbra] ha que jaz nas Seentas asso o Cubelo aqquem do rrio que parte com camynho pubrico e com congosta que vay pera o

${ }^{20}$ ANTT-Most. de Alcobaça, Livro 15, fl. 257v ${ }^{\circ}$.

ANTT-Mosteiro da Batalha, Livro 4, doc. 105 (2.V. 1471 ).

${ }^{22}$ Aforamento contratado por Luís Eanes do Juncal, escudeiro e procurador geral do Abade de Alcobaça. (ANTT-Most. de Alcobaça, $2^{2}$ incorp., m. ${ }^{\circ} 25$, n. $^{\circ} 632$ (65); de 19.VI1.1416).

${ }^{23}$ ANTT-Santa Clara de Coimbra, Caixa 4, Séc. XV, cota antiga: "n. ${ }^{\circ} 89 "$. (29. VI. 1366).

${ }^{24}$ ANTT-Santa Cruz de Coimbra. Livro 94, fls. 279 e 281 (ca. 1431 ). 
rrio e com o rrio e com vynha da dicta Ordem que trazia Martim Dominguez filho do Pegueyro"25.

Os rendimentos do sal-gema leiriense mereceram as atenções régias renovadas vezes. Em 1448, por exemplo, já D. Afonso V recuperara para a Coroa a Quinta do Cirol, doada, 65 anos antes, pela mencionada Beatriz Dias ao Mosteiro de Alcobaça. O documento menciona expressamente as "casas e oliuaees e marinhas em çertos lugares desuairados e huuã quintãa que chamam de çirol os quãees beens foram de huuã Briatiz Diaz criada del Rey dom pedro meu visavoo e foy achado per El Rey dom joham meu avoo cuja alma deus aja que pertençiam a elle e a coroa dos nossos Regnos e nom ao musteyro d alcobaça a que os a dita briatiz diaz deixara" . Todos esses bens seriam aforados, naquele ano, a Diogo Alvares por 2500 reais ano ${ }^{26}$.

D. Afonso V, contudo, não guardaria muito tempo para si as rendas reais do sal em Leiria, doando-as ao Conde D. Pedro de Meneses em $1463^{27}$. Apesar disso, a propriedade régia continuaria a contar com salinas de sal-gema na região. No foral manuelino de Leiria, de 1510, por exemplo, ainda se arrolam 18 talhos de sal nas "Sentas", além do quarto que pagavam a el-rei todos quantos ali o produziam ${ }^{28}$.

\section{2-A produção de papel em Cernache por 1431.}

A Coimbra que fervilhava de actividade comercial nos alvores

ANTT-Santa Clara de Coimbra. Caixa 1, Séc. XIV, cota antiga: "n. ${ }^{\circ}$ 69".

${ }^{26}$ ANTT-Estremadura. Livro 7, fls. 47-48 (17.VI. 1448).

ANTT-Chancelaria de D. Afonso V, Livro 9, fl. 132.

${ }^{28}$ Foral com várias edições. Consulte-se a de João Cabral, Anais do Município de Leiria. $2^{a}$ ed., Leiria, Câmara Municipal, 1993, vol. I, p. 38. 
de Quatrocentos, rendida a uma corte ducal culta, experimentava bom número de novidades tecnológicas impulsionadas certamente, e em parte, pelo saber informado e moderno do "estrangeirado" Infante D. Pedro ${ }^{29}$. Desde cedo, aliás, que em Coimbra o domínio técnico de represas de águas, da construção de engenhos de panificação, da regularização do leito do Mondego junto à cidade ou da construção de pontes longas e de difícil lançamento, obrigava à estadia na cidade de bons mestres construtores, seja nas tecnologias hidráulicas, seja na engenharia civil. Não admira, assim sendo, encontrarmos, na Coimbra ducal, Pero Afonso da Azenha, tabelião e "Mestre de Águas" especializado em hidráulica, que fez edificar "duas azenhas em Coselhas onde nunca foram fectas", planificando também, debaixo do patrocínio do Infante D. Pedro, as condutas de elevação das águas da Fonte Nova para o adro da Sé e para a Praça da cidade. Projecto malogrado, apenas, pela tenaz oposição dos crúzios, que fizeram derrubar toda a obra iniciada ${ }^{30}$.

Mas a Coimbra medieva, centro multifacetado de numerosos institutos eclesiásticos produtores de escrita, de bom número de cartórios notariais, de residência frequente de reis e nobreza, tinha também os seus trunfos tecnológicos em termos de produção maquino-facturada de materiais de escrita, fosse o pergaminho, fosse, o que é menos conhecido, o papel de trapo.

O fabrico de papel em Cernache, aliás, não deve deixar de se relacionar quer com o Mosteiro de Santa Cruz, quer com a presença

${ }^{29}$ Sobre a presença deste Infante em terras coimbrãs leia-se, por todos, Maria Helena da Cruz Coelho, "O Infante D. Pedro, Duque de Coimbra", Biblos, Vol. LX1X (1993), Coimbra, pp. 15-57.

30 Anais, Crónicas Breves, Memórias Avulsas de Santa Cruz de Coimbra (cd. de António Cruz), Porto, Biblioteca Pública Municipal, 1968, pp. 121-123. 
do Infante D. Pedro por terras mondeguinas, onde agiu como rico senhor e dinamizador da economia desse seu ducado.

Em Portugal, como se sabe, o papel é utilizado largamente já no século XIII como se pode ajuizar das referências inseridas na diversificada documentação da época. Infelizmente, contudo, apenas chegou aos nossos dias um exemplo concreto do seu uso numa notícia notarial redigida por Vicente Rodrigues, na povoação de Seda (Alentejo), em 1268 ${ }^{31}$. O que é mais raro na história medieval portuguesa, no entanto, é documentar-se o seu fabrico dentro do território nacional ${ }^{32}$.

Até hoje, os historiadores apenas têm podido referenciar o fabrico de papel na cidade de Leiria. Foi nela, efectivamente, que D. Gonçalo Lourenço de Gomide, escrivão da puridade de D. João I, terá instalado um engenho e artifício de fazer ferro, serrar madeiras, pisar burel e fazer papel. Esses engenhos devem ter sido, na verdade, montados, ao menos na parte referente à produção de pasta de papel de trapo. Diferentes notícias soltas na documentação daquela cidade das décadas de 1430 e 1440 disso dão certeza. Em 2.XI.1433, habitava nela um João Peres do Papel $^{33}$; em 1435, ou pouco após, apresenta-se-nos uma Leonor Rodrigues, a Trapeira, foreira, de Alcobaça, de certas terras nas Olhalvas, junto a Leiria $^{34}$. Sabe-se, ainda que Lucas Eanes, vassalo do rei D. João I e oficial de larga carreira nos cargos da administração pública regional leiriense, construiu, antes de 1433, um engenho de pisar

Publicado, entre outros, por Martim de Albuquerque, A Torre do Tombo e os seus Tesouros, Lisboa, Inapa, 1990, p. 110.

${ }^{32}$ Vd., por todos, A. H. de Oliveira Marques, Portugal na Crise dos Séculos XIV e XV, Vol. IV de Nova História de Portugal (dir. Joel Serrão e A. H. de Oliveira Marques), Lisboa, Presença, 1986, pp. 52-53.

ANTT-Most. de Alcobaça, $1^{\mathrm{a}}$ incorp., $\mathrm{M}^{\mathrm{o}} 38, \mathrm{n}^{\mathrm{o}} 30 \quad$ (2.XI.1433).

${ }^{34}$ ANTT-Most. de Alcobaça, Livro 15, fls. 224-224v ${ }^{\circ}$, 
burel sobre as ruínas de uma antiga azenha, prejudicando, na tomada das águas, o abastecimento dos veios que as levavam aos moinhos de Santa Maria de Alcobaça nesta localidade ${ }^{35}$. Mas não tem de ser, necessariamente, um engenho predestinado ao fabrico de pasta papeleira.

Que o papel se fabricava na cidade do Lis, ou, no mínimo, que aqui era procurado para compra, colhe-se, ainda, das aquisições que o Mosteiro de Alcobaça fez na cidade nos anos de 1438-40, entre as quais se registam despesas na compra de papel "pera a despesa da casa" e também de açafrão. A mercadores judeus leirienses, aliás, comprou regularmente Alcobaça resmas de papel nesses mesmos $\operatorname{anos}^{36}$. Nas Cortes de Lisboa de 1439, os procuradores leirienses alegavam não se saber que imposto aplicar num engenho de papel instalado junto ao Lis, de cujas águas tirava a força motriz para movimentar o seu pisão de moer trapo ${ }^{37}$.

Aos netos de Gonçalo Lourenço de Gomide permitiu o Regente D. Pedro, em 1441, terem ao seu serviço um trapeiro que lhes acarretasse pano para o moinho do papel de que eram herdeiros ${ }^{38}$. Mais tarde, noticia-se residirem em Leiria um Gil Afonso, do Papel (1464), e um João Pires, trapeiro (1501 $)^{39}$. Sinais, porventura, de que se continuaria a fabricar papel na povoação. Em 1519, Alcobaça aforaria a Galiote Pereira um moinho "que estava na dicta villa abaixo do moinho do papel Junto do Açude e abaixo da

${ }^{35}$ ANTT-Most. de Aloobaça, 2" incorp., M. ${ }^{\circ}$ 70, doc. 52; Id., Dourados de Alcobaça, Livro 3, fls.104-105 (18. XI. 1433).

${ }^{36}$ ANTT-Most. de Alcobaça. Livro 14, fl. $287 \mathrm{v}^{\circ}$.

"Documento referenciado por Sousa Viterbo, Gama Barros e outros autores. Remetemos para A. H. de Oliveira Marques, op. cit., p.52, onde se expõe bibliografia pertinente sobre o assunto.

${ }^{38}$ ANTT-Chancelaria de D. Afonso V, Livro 2, fl. 96 (27.11.1441).

${ }^{39}$ ANTT-Most. da Batatalha, Livro 4, docs. 181 (28.XII. 1463) e 90 (6.VIII. 1501). 
leuada principal" ${ }^{40}$. A documentação moderna permitirá reconstituir, praticamente de forma ininterrupta, até à actualidade, estes velhos moinhos do papel, junto da Ponte dos Caniços, os quais ainda hoje laboram, posto que apenas para farinação de cereais, observando-se na sua estrutura arquitectónica elementos primitivos góticos que denunciam a sua origem medieval.

Encontramos, como referimos, uma notícia documental que prova a produção de papel nas imediações de Coimbra. De facto, era na povoação de Cernache que se localizavam uns "artefícios de fazer papel", activos em 1431, ano em que foram registados no tombo dos bens de Santa Cruz de Coimbra ${ }^{41}$. Esta indicação, curiosamente, aparece contextuada, pois que estes engenhos de Cernache vizinhavam fornos ("fornalha") certamente de fundição de metal ou de cozedura de cerâmica, não se sabe, erguidos em local categoricamente chamado Inferno.

Não é possível afirmar de forma definitiva que o "artefício de fazer papel" de Cernache era propriedade do Mosteiro de Santa Cruz ou doutro senhorio. Apenas se noticia que partia com prédios daquele instituto, nomeadamente com o Paço que o Mosteiro crúzio ali tinha.

Associar-se-ia, em Cernache, o "fazer ferro" com o fabrico de papel, como, aliás, se colhe da carta de 1411 relativa a Leiria? A documentação crúzia não responde de forma satisfatória a esta questão, ficando para a arqueologia o esclarecimento mais cabal desta asserção. As referências que o documento encerra relativas a escórias, a carvoeiros e a carvão da zona de Cernache, no entanto, levam a crer que a "fornalha" do Inferno teria hipotéticas funções

${ }^{40}$ ANTT-Most. de Alcobaça, Livro 135, doc. 65, fls. 81v ${ }^{\circ}-83$.

Publicamos este documento em apêndice. 
de fundição de ferro ou de queima de carvão. Em qualquer das hipóteses, no entanto, deve sublinhar-se a importância da proximidade destes engenhos face a veios de água que, seguramente, seriam usados como elementos propiciadores de energia hidráulica que se aplicava na produção manufactureira de papel ou de certos minérios.

De qualquer modo, os elementos agora apresentados constituem mais um contributo para o conhecimento das actividades maquinofactureiras e paraindustriais de Portugal medieval, impondo o eixo Cernache-Coimbra como um segundo e raro centro produtor de papel e doutras produções minerais da maior importância para as economias urbanas das cidades daquela época. 


\section{DOCUMENTO}

1431, Coimbra - Relação de algumas propriedades do Mosteiro de Santa Cruz de Coimbra em Cernache, mencionando-se um "artifício do papel", e uma "fornalha" no sítio designado Inferno.

ANTT-Santa Cruz de Coimbra, Livro 94 ("Livro Nobre"), fis. $168 \mathrm{v}^{\circ}-171$

[Fl. $168 \mathrm{v}^{\circ}$ ]

Jtem mais huum casal que foy de fernam galego $\mathrm{E}$ a cabeça deste cassall sta ante a porta da fornalha e chamam o casal do Jnferno. E trazeo afomso perez d almalagez e Jaz em canaueall.

$[\ldots]$

[Fl. 171]

Jtem mais o paaço de sancta cruz e parte com a Rua que uaj pera os moynhos E pera o artefiçio do papell e com o pomar do Jfante e com o Ribeiro e com a almoinha do Jfante, E o paaço sta na meatade e senhas casas baixas aa Jlharga delle.

Jtem huuã cassa que traz martim da anoura Junto com a de girai biçente. E estas cassas som anbas de sancta cruz e girai biçente traz huuã E a outra martim da anoura E partem com a Rua, pubrica que uaj pera o papell e com a almoynha de carassco // [Fl. 171 v $\left.{ }^{\circ}\right]$ E contra aguiam partem com agua corente E estas casas partem a chãao do Resio e fazem dous foros,

$<$ E esta casa que traz girai uiçente ora trazjoam afomso a que a deu, E a outra cassa que trazia martim da anoura, he da molher de afomso perez d almalagues ${ }^{42}>$.

\footnotetext{
${ }^{42}$ Esta frase é de mão diferente, tendo sido escrita posteriormente aos registos de 1431 .
} 
Jtem huuã cassa que traz aluaro biçente e parte com adegua de martim moseeiro e com a Rua que uaj pera os moynhos e com cassa de pero negro,

<ora a traz sua molher. ${ }^{43}$ >

Jtem a cassa de pero negro parte com a Rua pubrica e com outra cassa de aluaro biçente e com almoynha de sam bras. E esta cassa faz dous foros.

<Jaz em pardeeiro e nom ha hi ereo nhuum. ${ }^{44}$ >

Jtem a cassa da fornalha que jaz aalem do Rio dos moynhos e parte com o Rio e com a Rua pubrica e com os canaueaees das almoinhas.

Jtem huum pardeeiro que traz afomso perez que he posto em canaueall que chamam o Jnferno e Jaz ante a porta da fornalha e faz huum foro.

Jtem huum pardeeiro que he posto em canaueal que traz gil stevez e parte com a Rua pubrica e com os outros canaueaees e com a fornalha e com o pardeeiro da egrela e faz huum foro.

$<$ moreo e casou sua molher com gonçalo Ribeiro de urzelhe. ${ }^{45}>/ /$ $[\cdots]$

[Fl. $\left.175 \mathrm{v}^{\circ}\right]$

[Uma almuinha] $<$ E ora a traz fernam $\operatorname{carvam}^{46} .>/ /$

[Fl. $\left.176 \mathrm{v}^{\circ}\right]$

${ }^{43}$ De mão posterior.

${ }^{44}$ De mão mais tardia.

${ }^{45}$ De mão posterior.

${ }^{46}$ Mão posterior aos registos de 1431 . 
Jtem almoynha de martim biçente o mosqueiro e parte com cassa d aluaro biçente e com a Rua que uay pera a azenha e pera a fornalha.

Jtem mais biçente gato traz tras a fornalha huuã almoynha e parte com girai biçente e da outra com o Rio e parte na fornalha e entesta no canaueall de gil stevez.

$<$ que traz canaueall. ${ }^{47}>/ /$

\section{[Fl. $177 \mathrm{v}^{\circ}$ ]}

Jtem biçente barqueiro traz huuã almoynha $\mathrm{E}$ parte com andre martjnz e com o pintado e com o escoyrall e com camjnho que uaj pera as binhas E porque asy ${ }^{48}$ se acabam.

$$
[\ldots] / /
$$

